\title{
Is Evolutionary Biology Infected with Invalid Teleological Reasoning?
}

\author{
A Review of Not by Design: Retiring Darwin's Watchmaker \\ by John O. Reiss, University of California Press, 2009
}

\author{
David 7. Depew
}

\begin{abstract}
In Not by Design: Retiring Darwin's Watchmaker (2009), John Reiss claims that thinking of organisms as analogous to artifacts, and so thinking of natural selection as naturalized design, is not the only point at which invalid and unsound teleological reasoning has affected evolutionary biology. Teleological errors persist whenever evolutionary biologists turn the observation that an organism would not exist unless it possessed a certain trait into the claim that the trait in question came into existence because it had this salutary effect. Since he thinks fitness itself is often measured in ways that commit this fallacy, Reiss infers that the only good measure of fitness is the continued existence of populations or species, a principle he traces back to the anti-evolutionary 18th century comparative anatomist George Cuvier. In this essay, I explicate Reiss's reasons for coming to this conclusion and offer challenges on several points. Among these is Reiss's perhaps too hasty dismissal of the consequence etiological or selected-effects account of adaptedness. I conclude by suggesting that Reiss's work exemplifies one way in which evolutionary developmental biology (Evo-devo) is currently affecting the consensus form of genetic Darwinism that has prevailed for many decades under the name of the Modern Synthesis.
\end{abstract}

\author{
KEYWORDS \\ Alberch (Pere) $\bullet$ Conditions of (for) existence $\bullet$ Consequence etiology $\bullet$ Cuvier \\ (George) $\bullet$ Darwin-Wallace principle $\bullet$ Evo-devo $\bullet$ Fitness $\bullet$ Functions \\ (biological) • Natural selection $\bullet$ Teleology
}

\section{An Ambitious Gritique}

John Reiss is a practicing evolutionary biologist (herpetology) who by his own account happened to be in the right place (Harvard's Museum of Comparative Zoology) at the right time (the 1980s) to hear echoes of the debate about sociobiology that had been raging there between E. O. Wilson and, on the other side, Stephen Jay Gould and Richard Lewontin (xiv). Reiss is not concerned with sociobiology, at least in this book, but with the adaptationism that Gould and Lewontin saw in the sociobiologists' approach to cooperative behavior. At Harvard, Reiss was guided by Pere Alberch, in whose laboratory Gould's stress on

$\S$ Project on the Rhetoric of Inquiry, Bowman House, University of Iowa, Iowa City, IA 52240, USA

E-mail: david-depew@uiowa.edu

Received 18 July 2010; Revised 29 November 2010; Accepted 4 December 2010 
developmental constraints was being transformed into a now influential version of the Evo-devo movement (xiv, 327). On Alberch's view, which Reiss accepts, variation in the rate, timing, placement, and intensity of gene products during the ontogenetic process, rather than mutation in structural genes, constitutes the proximate source of the phenotypic variation on which natural election works (327-29). Reiss does not think that Evo-devo, at least as he construes it, does away with natural selection. Rather, he seeks to identify the role played by selection in retaining or eliminating the variation generated in the developmental process. Selection, he argues, enables organisms, populations, species, and other lineages to maintain the presumptively adapted conditions of existence to which their very persistence already testifies. "Adaptedness," Reiss writes, "is not a product of evolution; it is a condition for evolution" (22). He thinks that this fact, as he takes it to be, belies the adaptationist assumption that organisms are collections of independently optimal adaptations that arise by way of concerted spurts of directional selection. "It is a mistake," he writes, "to atomize organisms and to explain each part as the solution of a problem raised by the environment" (295).

But this is only the beginning. It is not just adaptationists of the sort upbraided by Gould and Lewontin whom Reiss criticizes. He argues at considerable length that Darwin himself retained elements of the intelligent design model that he attacked; that the same assumptions lurk within the Modern Synthesis; and that even as ardent an anti-adaptationist as Gould himself was not entirely free of them (295).

Why Reiss comes to these startling conclusions is surely the main thing that readers of this book or this review essay will want to know. So answering this question will be my focus. I will, however, pose some questions along the way.

Reiss's intended audience is primarily his fellow biologists and students of biology, who on his view need to know just how contaminated by the argument from design their interpretive habits are before they can change them. Philosophers and historians of biology are sometimes brought in as witnesses, but more often than not they, too, are said to fall into the fallacy that is Reiss's topic from beginning to end. This is the fallacy of inferring from the fact that a given sort of organism would not exist unless it possessed a certain set of traits to the conclusion that these trait come into existence just because they contribute to the actual or probable existence of the organisms that have them. This inference assumes that organisms are assemblies of traits. Having done so, it repairs its invalid slide from treating traits as necessary conditions for organic functioning to claiming that they come into being for this purpose by supplying a tacit premise that the 18th century philosopher Gottfried Leibniz called "the principle of sufficient reason." The principle that everything that happens has to happen and for that reason must be a Good Thing served Leibniz as an allpurpose warrant for giving deductive-sounding, but value-laden reasons for the existence of entities, properties, and states of affairs of the sort satirized in Voltaire's Candide. This high-handed and high-minded premise does make what Reiss calls "deterministic teleology"-I would prefer to call it deductive or demonstrative teleology - valid. But it also makes it unsound, question-begging, and empty in ways that Gould and Lewontin, channeling Voltaire, ridiculed in their famous polemic "The Spandrels of San Marco and the Panglossian Paradigm" (Gould and Lewontin 1979). Most of Darwinism, Reiss argues, still shows signs of this fundamentally theological fallacy.

The book is divided into four parts. The first sets out the propositions I have summarized and lays the groundwork for Reiss's contention that hard-to-recognize forms of unsound teleological reasoning continue to dog contemporary biology, especially in how fitness is measured, biological functions are defined, and selection is conceived. The second part is a detailed intellectual history of "How We Got Into This Mess." The third is an attempt to show that traces of the unsound teleology whose history is reconstructed in the second part are still found in concepts dear to the heart of the Modern Synthesis: adaptive landscapes, genetic loads, and genetic drift. The fourth part applies Reiss's proposal to micro- and macro-evolutionary problems. In it Reiss (i) defends continued existence as the only tractable measure of fitness; (ii) treats the continued existence of populations, species, or other lineages as sufficient evidence that they are fulfilling their conditions for existence; (iii) conceives of "broad-sense" natural selection as maintaining rather than creating adaptedness and so as equivalent to the principle of conditions of existence; and, (iv) regards developmental responses to environmental shifts as the most important source of the new forms that natural selection broadly construed evolves. 


\section{A Surprising Hero}

Since I am not a practicing evolutionary biologist, I am not in a good position to comment on how well received Reiss's criticisms of current interpretive practice in his field might or should be. As a philosophically minded historian of evolutionary theory, however, I can say that I found his tour through the history of biological teleology's misalliance with natural theology in his chapters on "How We Got Into This Mess" informative and for the most part persuasive. I agree that the design inference that Darwin criticized in William Paley and the Bridgewater Treatises was in fact first proposed in its modern form by Leibnizians such as the influential textbook philosopher Christian Wolff (1679-1754). Wolff explicitly held that the cosmos is structured in accord with the old "principle of plentitude" according to which being is inherently good. Since being is good, Wolff argued, it is maximized and since it is maximized it comes in a continuum that stretches from the purely rational down through various grades of the organic to the purely material. The principle of sufficient reason was an interpretive maxim that was supposed to help people apply the principle of plentitude to particular phenomena in this "great chain of being." These phenomena might or might not have included finding purpose and design in apparently bad phenomena such as the Lisbon earthquake, whose singular fame among earthquakes springs from the fact that it occurred just when these theological-philosophical musings were being debated across Europe (see Neiman 2002).

In the post-Newtonian, British uptake of the argument from design one can see both the principle of plentitude and the deductive form of the argument from design slowly disappearing into or rather hiding themselves behind a pseudo-empirical, inductive form of natural history whose culminating stage, but far from last gasp, was Paley's Natural Theology (1801), which in his Autobiography Darwin confesses to having practically memorized when he was an undergraduate at Cambridge. Preachers like Paley could persuade people to see the fittingness of organic traits to the lives of organisms in specific environments as signs of God's providence. But scientists could hope to turn examples such as those Paley stacked up like cordwood into genuine biological knowledge only if there is a demonstrative or deductive relation between any particular case and the principle that Nature or Nature's God, being good, provides organisms with the good-making traits they need to live their lives. What Reiss calls "deterministic teleology" covertly relies on Leibniz's deductive theodicy to convert the realization that an organism could not survive if it didn't have such and such traits into a sufficient reason why these traits came to exist and were incorporated into the ontogeny of this or that species.

Reiss thinks that in spite of himself Darwin remained captured by this picture. So he does not observe the customary pieties of evolutionary biologists by treating Darwin as his hero. Instead, the surprising hero of his book is the pre-evolutionary, indeed anti-evolutionary, comparative anatomist George Cuvier (17691832). Cuvier is his hero because he restricted teleological reasoning to identifying the conditions that must be satisfied if an organism or lineage is to persist. Why, you might ask, should these conditions have any teleological import at all? The answer is that for Cuvier harmonious and functionally end-oriented mutual support among its parts rather than, as for Darwin, the de facto availability of appropriate environmental resources defines an organism's conditions of existence (136-37). Unless its web of mutually supportive traits is brought into being through an end-oriented developmental process - epigenesis in the classical sense of the term - the proximity of an organism to potentially useful external resources means nothing. For Cuvier, accordingly, the very fact that a certain species is or for a time was extant is sufficient to warrant with demonstrative strength the conclusion that its parts are or were lending 'reciprocal help to each other.' This is so because, as Cuvier writes, "appropriate harmony among the organs acting upon one another is a necessary condition for the existence of the being to which they belong. If one of these functions were modified in a way incompatible with the modification of others that being could not exist" (quoted in Reiss, 100).

Reiss's advice to his fellow evolutionary biologists is: "Go thou and do likewise." As in Cuvier's nonevolutionary biology, evolutionary biologists can and should say no more than that satisfaction of a species' conditions for existence (as Reiss chooses to translate conditions d'existence) means that so far forth its members are fit or adapted. Adaptedness so construed is a presumption of living things insofar as they are living. It is not a precariously achieved state in which, under the influence of counter-entropic "forces" like natural 
selection, an organism, population, species, or other lineage advances for the time being and against all odds from a presumed state of non- or mal-adaptedness to one of adaptedness (or worse "optimal" adaptedness) into which it might easily fall again. I would put this point even more strongly than Reiss does. A wrongheaded picture of presumed non-adaptedness based on a misplaced analogy between organisms and artifacts explains why "deterministic" design teleology insinuates itself into evolutionary biology even against its will. The assumption is that something must be working to defeat the null hypothesis of non-adaptedness. Our imperfectly post-Christian culture tends to make the argument go the other way around. In order to retain an intelligent designing God organisms are generally treated as assemblages of parts by analogy to designed artifacts. But that is no reason for biologists to buy into this picture (22).

In claiming that Cuvier's principle of conditions for existence is relevant to contemporary evolutionary biology Reiss argues that evolutionary changes can and do go on so long as overall adaptedness is maintained throughout the process (266). But he realizes that he cannot without equivocation appeal to Cuvier's principle to ground this claim unless he rebuts the well-entrenched view that Cuvier was justified in thinking, as he did, that his kind of holism about the relation between organisms and their parts logically rules out species transformism from the start. The general line of argument for this anti-evolutionary conclusion is that organisms are so integrated that the effect of a significant change in one part on all other parts will destabilize the whole such that it will be unable to satisfy its conditions for existence and so will meet the fate of the fossils in the Paris chalk whose reconstruction provided the basis of Cuvier's considerable fame. (Intelligent design proponents like Michael Behe are still dining out on this old topos.)

Reiss meets this burden by intervening in a controversy about Cuvier's sources. The received view is that Cuvier was an Aristotelian (Coleman 1964). To be sure, Cuvier's conception of teleology is, like Aristotle's, one in which internal end-orientedness guides the process of ontogenetic differentiation. It is not the intentional design of functional artifacts. Reiss notes, too, that Cuvier's concept of conditions for existence is very close to Aristotle's idea of hypothetical or conditional necessity (105). Paraphrased slightly, Aristotle says that even if we cannot deduce an organism's traits from prior knowledge of its essence, we should at least be able to say that without such and such parts it would not be able to exist (Parts of Animals I.1.640a33-b.4). But this Aristotelian interpretation makes it too easy to trace Cuvier's opposition to evolution back to a version of metaphysical essentialism so strong that, as in Aristotle, it blocks off the very possibility of evolution and allows evolutionists to write off Cuvier as a mossback.

Luckily, there are at least two problems with this reading of Cuvier. One, which Reiss does not mention, is that it is too strong. It not only blocks off the possibility of evolution, but of extinction. For the Stagirite father of biology species have either existed always or never existed at all. It would be very strange, however, for a man like Cuvier, whose lifework was built on the fact of extinction, to entertain such a view.

The other objection to the Aristotelian interpretation of Cuvier, which Reiss develops in considerable detail, is that there is little evidence for the Aristotelian reading of Cuvier and a great deal instead for the influence of Immanuel Kant. This influence, Reiss argues, means that the principle of conditions of existence need not have the anti-evolutionary implications that Kant and Cuvier themselves happened to draw from it.

Guvier hailed from Wurttemberg, the same interestingly bilingual (French and German), religiously divided (Catholic and Protestant), and politically fractious (monarchs and estates) region in which his contemporaries Hegel and Schelling grew up. (They might have gone to the same seminary if Cuvier had not flunked the exam and gone instead to the administratively-oriented Karlsschule [87]). Drawn to Paris though he may have been, Cuvier knew German biology at its crucial, formative stage. Kant, working with the biologist J.F. Blumenbach, defined organisms as "natural purposes" whose parts are mutual conditions of each other's existence. He inferred from this that organisms cannot be assembled from separate, independently formed components, as artifacts can be, but must emerge through a developmental process. (This disanalogy is one reason why Kant regarded the argument from the apparent design of the natural world to the existence of a designer as invalid.) Cuvier's conditions d'existence, as E.S. Russell noted long ago, refers to just such an emergent "coordination of the parts [of a developmental system] to form a whole" (Russell 1916, 239; see Reiss, 136). Reiss's point is that on this historically well-supported interpretation, unlike the reading that links him to Aristotle, Cuvier's principle can tolerate evolution even if Cuvier personally (and politically) could not. Reiss might have reported that this possibility becomes even 
more likely because Kant famously denied that being is a predicate - the verb 'to be' is a mere logical connective or operator - and so does not come in higher and lower degrees, as the great chain of being idea demands. As Kant realized, this means that the principle of conditions of existence is only a heuristic and interpretive directive to inquire into particular cases by assuming that organisms are functionally integrated wholes. It is not a metaphysically armored essentialist definition of organisms, as it is in Aristotle. So Reiss may be on solid ground in thinking that species can lose and acquire novel traits leading to speciation events so long as their conditions for existence continue to be maintained throughout the process (266). The traits do not necessarily have to be built by natural selection for this to occur. What is important is not how they got there but that they got there somehow. In this case, the evolutionist must take as a guiding question, "What are the properties of developmental systems that allow ... continuing evolution to occur while constantly maintaining functionality and how have these properties themselves evolved?" (330). Solid evidence that this is possible, I note, has been emerging from contemporary evolutionary developmental genetics, in which genetic systems are typically well enough buffered against disruptive change to allow some copies of gene families to vary in ways that lead to enhanced (or if you prefer maintained) adaptedness while others mind the functional store. Similar ideas are at work in more phenotypic and morphological veins in the concepts of phenotypic plasticity, modularity, robustness, and evolvability that figure in contemporary evolutionary theorizing.

\section{Was Darwin a Design Teleologist in Spite of Himself?}

While Darwin is not Reiss's hero, neither is he a villain. Darwin, I might point out, revered Cuvier as one of his "three gods" (Darwin to William Ogle, February 22, 1882; the others were Aristotle and Linnaeus). On Reiss's reading, Darwin and Wallace were adding to Cuvier's principle of conditions for existence a second principle of "the continued existence of traits," which are maintained by what Darwin called "the strong principle of inheritance" combined with environmental utility under conditions of scarcity (283). Reiss's implication is that evolutionary biologists can and should appeal to the DarwinWallace principle as they go about their work to answer the more basic question raised by Cuvier's principle about how adaptedness is maintained through evolutionary change. Unfortunately, however, Darwin's analogy between natural and artificial selection tended to reverse the priority of what are in reality complementary principles. Indeed, to the extent that this analogy implies that a designing power - if not God, then natural selection - must be out there somewhere making traits to fit organisms into preexisting niches, Reiss argues that Darwin made the existence of organisms too dependent on the acquisition of adaptations, thereby separating adaptation from existence and treating any existing organism as "poorly adapted ... because ... it might be 'modified with advantage' to meet some future contingency" (140, with embedded quotations from On the Origin of Species). On this score, Reiss says that Wallace, who denied the analogy with the breeder's art and thought the argument from design should be dismissed out of hand rather than reformulated naturalistically, did much better than Darwin, at least until he eventually knuckled under to the Darwinian party line (141-45). In future work, Reiss or someone else might use this insight to reinterpret Wallace's stress on adaptation by natural selection, which is more marked than Darwin's, not as aiming at anything like contemporary adaptationism, but instead as showing that Wallace was doing what Reiss suggests - using the Darwin-Wallace principle to show how Cuvier's principle is satisfied.

Why, we might ask, does Reiss think, as he apparently does, that the consistency of Cuvier's view of organisms with evolution and its possible consonance with the Darwin-Wallace principle was not appreciated by British evolutionists? To the extent that Reiss addresses this question his answer is historical. He points out that the British way of receiving Cuvier was distorted by the highly ideological revival of natural theology that prevailed during England's hot and cold wars with Revolutionary and then Napoleonic France. Following Russell and others, he argues that Cuvier's principle of conditions for existence was misinterpreted in this ideological milieu by Darwin, among many other British naturalists, to refer to the external environmental conditions into which an organism is presumably inserted and to which it must be adapted (fitted) if it is to live and reproduce (136). Reduced by Darwin to a "mysterious correlation of parts," developmental integration thus ceases to be the defining mark of organisms - and the basic meaning of final causality. 
On the whole I think this is well said. I might point out that one of Darwin's teachers, Robert Jameson, was Cuvier's English translator and that in putting a creationist spin on his work he also put an externalist spin on conditions of existence. Still, I am not sure that Darwin deserves as much blame for perpetuating or extending this conception as Reiss intimates. Reiss's treatment of Darwin may be insufficiently responsive to scholarship that distinguishes between the rhetoric of the Origin, which was indeed pitched for strategic reasons against the argument from design, and Darwin's long-standing orientation to ontogeny as the locus of variation-production and his view of natural selection as a mechanism for maintaining developmental adaptedness in the face of environmental change (Hodge 1985; Nyhart 2008; on Darwin's Origin, see Depew 2009). Besides, not every British biologist in Darwin's day was a Paley knock-off. Richard Owen, for example, who was styled by some, including himself, as "The British Cuvier," thought of Paley as a biological utilitarian and a philosophical primitive. Owen was working toward a theory of evolution that preserved Cuvier's principle when, much to his annoyance, he was upstaged by Darwin (cf. Brigandt 2009). Reiss does not mention him. Moreover, the separation of adaptedness from existence of which Reiss speaks feels to me like a backward projection of Weismann's separation of evolution from development onto a Darwin who, because he can ignore the role of development in evolution, is imagined as sanctioning and blessing the sort of design-without-a-designer adaptationism that has repeatedly been conjured up during the recent Darwin bicentennial.

\section{Is Genetic Darwinism Infected With Design Teleology?}

Even if we grant that Reiss is right about the externalist way in which Darwinism was initially received and subsequently disseminated (in contrast to the thorny question of 'what Darwin really thought,' the Holy Grail of many in "the Darwin industry"), we may still find ourselves wondering whether, even if publicsphere Darwinian polemics still focus obsessively on design talk, we can at least hope that practicing evolutionary biologists don't. Reiss argues, however, that this hope is unjustified. Deterministic design teleology, he claims, has long been lurking just under the surface of much professional, technical evolutionary biology as it has been guided and circumscribed by most versions of population genetical Darwinism.

Consider the following. As Lewontin has never ceased pointing out, if the environment is seen as existing prior to organisms that make a living off of it, rather than being co-created in the way contemporary "niche constructionists" insist, then organisms are likely to be construed as having to solve problems that an externally impinging environment poses to them. Since, contra Lamarck, organisms can't solve these problems by their individual efforts, they are solved instead by the gradual evolution of adaptations as higher reproductive rates spread through populations under the "force" of natural selection. In this picture, evolving populations are thought of as moving from a problematic state of non-adaptedness toward a goal-state of adaptedness in the very way Reiss calls into question. Moreover, this journey is tracked by means-end reasoning of the sort that is not only still around, but is flourishing in the form of optimization analysis, genetic algorithms, and so forth. To imagine this process without invoking some sort of intentional agent or at least his ghost, Reiss argues, is very difficult. As the title of his book implies, he thinks you can't have deterministic teleology as he defines it without the design concept — or, it appears, vice-versa. To make matters worse, goals are inscribed in a question-begging manner into the way environmentally posed adaptive problems are set up. End-points are already inscribed into beginning points (283). Accordingly, shadows of the design talk that made Darwin's theory a rival of natural theology rather than its gravedigger fall across heuristic devices such as Sewall Wright's adaptive landscapes, in which in order to climb adaptive hills a species must pass through maladaptive valleys (171-77). Shades of teleology can also be found, Reiss argues, in George Gaylord Simpson's and Walter Bock's treatments of macroevolution, in which a lineage that begins as dinosaur and ends as bird must pass through some sort of relatively nonadaptive "transition zone" (301-03).

Forget about it, as they say in the New York boroughs. According to Reiss, the concept of adaptedness at work in theories like Wright's and Simpson's (but not in Fisher's, whom Reiss credits with avoiding teleological mistakes by defining fitness as average reproductive success after the fact [186, 253]) involves treating the aptness of a structure for its contribution to the life of an organism as "evidence that it was 
designed for just this role" (124). To link adaptedness to intentional design in this way, Reiss says, is to treat the existence of organisms and lineages as inherently improbable and then obsessively, fruitlessly, and in the end theologically to call on the process of adaptation, led by natural selection aided by auxiliary evolutionary "forces" like genetic drift, to turn the improbable into the probable.

For Reiss, we can and should think of evolution as the way in which the adaptedness that dynamically matches traits to viable life styles is maintained across intra- and inter-specific change. The only useful measure of adaptedness so construed is, as Cuvier thought, the very existence of the organisms, populations, species, and wider lineages whose presumptively integrated suites of traits sustain their development, lifestyles, adaptability to environmental fluctuations, and reproductive prowess.

What Reiss calls "broad sense" natural selection tracks just this sort of continued viability. Selection eliminates organisms, populations, and lineages that do not stay within the "range of boundary conditions" that demarcate their conditions for existence (282). This does not mean that "medium sense" natural selection, which was developed by the Modern Synthesis and ranges over populations with different reproduction rates, does not exist or is not useful to evolutionary biologists. True, Reiss thinks that even if one can conceptually distinguish selection from genetic drift - he doubts it (233) - they are almost impossible to tell apart in practice. This blocks treating "selection of" as "selection for," and hence blocks medium sense selection from having causal explanatory force. (On this point, Reiss agrees without saying so with Matthen and Ariew [2002] and Walsh et al. [2002].) But, he continues, it makes no difference that one can't tell drift from selection if all that counts is "continued existence of characters in populations" in accord with the Darwin-Wallace principle (283).

Nor does Reiss disdain "narrow sense" natural selection. In well understood cases that do manage to identify "effects of distinguishing features on survival of classes" (280), such as perhaps the spread of the FY-0 allele of hemoglobin as a counter to malaria (274), the beaks of Darwin's finches, and even industrial melanism in pepper moths (273-277), Reiss acknowledges that causal "selection for" can, at least in principle, be identified (282-83). His implication is that this is nice work if you can get it, but even if you succeed in getting it what you have done is find how the characters of organisms have enabled certain organisms to remain within the boundary conditions that define their conditions of existence. The larger point is that both medium and narrow sense selection are in the service of broad sense selection. "Narrow sense natural selection is important ... not because it [causally] explains all 'adaptive' evolutionary transformations, but because it is a necessary part of the explanation of the continued existence of characters in populations" (283). Presumably, satisfaction of the Darwin-Wallace principle of character continuity is in turn important because it is a necessary part of showing how species and other lineages satisfy Cuvier's principle. Seen in this way, the teleological fallacy should be far less tempting.

Let me make two remarks about these claims. First, I offer a historical note. Reiss's ideas about medium versus narrow sense selection explain why he likes Fisher, or at least his own reading of Fisher. On this reading, Fisher counted average reproductive success after the fact as fitness and so avoided teleology. In this he differed from Wright, Dobzhansky, Simpson, and Bock, who discriminated between drift and selection in a vain effort to find causes at the population level and ended up instead falling into the teleological fallacy. Even if this is true, I cannot help mentioning that when Fisher's project is viewed as a whole, and not simply through the lens of his Fundamental Principle of Natural Selection, he appears to have thought of natural selection as big-time counter-entropic hill climbing and of eugenics as man's dutiful way of continuing God's process of creation in conditions in which nature had been disrupted or superseded by culture (Moore 2007). Seen in this light, Wright and Dobzhansky were actually trying to tone down Fisher's teleological impulses (and his eugenic enthusiasm).

Second, philosophers of biology will take note of Reiss's analysis of the relationship between biological functions and adaptations. Unsurprisingly, Reiss rejects the so-called etiological or selected effects view of functions, according to which biological functions are adaptations that have been created by directional selection for the purpose of performing some current physiological or behavioral job that has a positive effect on reproduction. He rejects this analysis not only because there are severe "epistemological limits on our knowledge of past populations" (283), but because this view is compromised by the illusory teleological causality that is Reiss's main quarry $(25,263)$. Knowing the origins of traits that contribute to maintaining conditions for existence is, in any case, less important than the fact that they have arisen. Consequently, Reiss 
analyzes biological functions in roughly the system-maintaining way pioneered by the philosopher Robert Cummins and developed recently by Arno Wouters (Wouters 2007). "[Biological] functions," Reiss writes, "are effects that are necessary conditions for [an individual organism's] continued existence" (25) quite apart from how they come to be. An implication, I think, is that without knowing that they are evolved adaptations the pre-evolutionary Harvey and Cuvier could still find and validate biological functions as well as Darwin or, say, Richard Dawkins. In fact, they did just that. In addition, the Cummins-Wouters-Reiss analysis of biological functions has the further advantage for Reiss of evading thinking that organisms, like The Little Engine That Could, are constantly huffing and puffing their way up adaptive hills (25, 263). Not looking obsessively for adaptations means that we do not have to engage in the nearly impossible task of finding their etiologies. We do not, Reiss writes, need to

try to decide on a particular historical cause of each feature and to consider natural selection by definition the explanation of all "adaptations." If we do so we necessarily accept a teleological view of natural selection as aiming from a past unadapted state to a present adapted state, when overall adaptedness is necessarily maintained throughout the process, whatever the causes (267).

The role-in-a-system analysis of functions certainly fits Reiss's stress on necessary conditions. Still, there are advantages for critics of design teleology to retaining consequence etiology of some sort, if that is possible. Such accounts depend entirely on the amplification of past reproduction-enhancing events rather than on any future-oriented appeals to intentions of the sort that for Reiss lead to, or come with, design teleology. On the etiological or selected-effects view, traits spread through populations because their historical precursors had reproductive effects in the past that increased the proportion of organisms that carried them. So consequence etiology, even if we decline to call it "biological teleology," evades at least one source - perhaps the main source - of the deterministic teleological illusion and the design paradigm.

I think an effort in this direction is warranted. I admit that there are many philosophical formulations of consequence etiology that do seem to project the offending picture Reiss sketches in the paragraph just quoted. However, the main problem with these formulations lies primarily in their attempt to causally explain particular adaptations on the assumption that they are the evolutionary equivalent of discrete biological functions. To me these two concepts should not be assimilated to each other (Depew 2007). When they are, two different claims, one misguided, the other not, get conflated. If you think evolving discrete adaptations is the most important process in evolution you will need detailed, but alas usually unavailable, knowledge of the history of a trait in order to determine whether it is an adaptation, an exaptation, or a concomitant result of selection for something else. If, however, you decline to think of organisms as bundles of adaptations, as Reiss does, and if you analyze functions in a role-in-a-system-no-matter-where-they-comefrom way, as he also does, it may still be possible to acknowledge that the overall adaptedness of organisms, populations, or lineages is maintained precisely because they have a history that sustains that adaptedness. The fact that one does not know that history, or at least much of it, makes no difference if one is not captured by the design paradigm and the search for adaptations. All that matters is that it did happen and happened in such a way that it resulted in beings able to satisfy their conditions of existence in what usually turn out to be very flexible ways. To that extent, the adaptedness or fitness that is warranted by continued existence is etiologically grounded and caused.

It is worth pointing out in this connection that some philosophers think that the consequence-etiological analysis of biological functions, precisely because it departs from the design paradigm, actually requires the kind of developmental holism about organisms that Reiss promotes (McLaughlin 2001). To get rid of design and its adaptationist doubles in this way one may have to call on dynamical models of complex selforganization to provide a suitable framework for picturing (and mathematizing) organisms as inherently adaptive developmental systems (Depew and Weber 1995). I think Reiss's preference for an Epicurean-style metaphysics of organisms may lead him astray on this point $(32,356)$. Empedoclean-Epicurean-Lucretian materialism certainly contrasts with and throws doubt on design talk. But it also makes the etiology of organisms, species, and lineages a series of accidents. Adaptive traits do not arise in order to deal with environments, but just happen to have adaptive effects that are retained by environments (284-85; see Depew 2007). I hope Reiss doesn't think that happy accidents are causal stories or etiologies. If he did he 
would be begging the question about the inaccessibility of the past that his analysis strongly requires him to leave open. Intriguingly, Reiss ascribes Epicurean metaphysics, and so an implicitly accident-prone etiology, to Cuvier $(112,285)$. However that may be, I doubt whether an evolutionary Cuvier would hold it. I imagine that an evolutionary Cuvier, like an evolutionary Kant, would agree that the evolved ability of complex adaptive systems to adjust to changed circumstances rules out happy accidents just as much as it rules out thinking of organisms as assemblies of discrete adaptations by an analogue of conscious design.

\section{Was Gould an Adaptationist In Spite of Himself?}

I can see how Reiss's objections apply to the kind of genetic Darwinism advocated by Dawkins, the sociobiologists attacked by Gould and Lewontin, and more recently evolutionary psychologists. These socalled "adaptationists" rely heavily on optimization models that do indeed presuppose that natural selection is a counter-entropic "force" that drives populations up the side of what Dawkins revealingly calls "Mount Improbable" (Dawkins 1996). Such models typically do treat organisms as collections of independently optimized traits and do rely, as Reiss says, on a strong analogy between organisms and artifacts. In the process they probably do smuggle in under cover of seemingly innocent metaphors traces of the old theological doctrine of creatio ex nihilo.

I am less sure, however, that practicing evolutionary biologists or the mathematical methods and models in which they are schooled are necessarily compromised by design teleology. It is not clear, in the first instance, how ontologically committed muddy-boots evolutionary biologists have to be in order to go about their work productively, as Reiss clearly wants to do, but with a clean philosophical conscience. But even if their models and methods are inseparably connected to larger evolutionary theories, which are indeed ontologically committed, I have raised in the preceding section the possibility that the design-without-adesigner paradigm is merely one or at most a family of interpretations of genetic Darwinism. There are also, among others, etiological interpretations. These evade the design paradigm even if Reiss is right that they fail to evade the deterministic notion that external environments mold adaptive traits. What I am still unconvinced of is Reiss's claim that design teleology has tucked itself away in any and every conception of evolution that reduces conditions of existence to external, environmental conditions of existence, thereby implying that etiological accounts offer a distinction without much of a difference. He has, however, made about as good a case for that proposition as anyone is likely to make.

What, then, of the accusation that Gould himself covertly retained adaptationist assumptions? Reiss's reason for saying so concerns Gould's conception of developmental constraints. Gould thought of them as something that adaptive natural selection wants to find a way around. They are like old, deeply rooted, gnarly tree stumps around which farmers must plow. The stumps themselves are largely the result of previously successful evolutionary novelties that selection has successfully locked in by entrenching them in the developmental programs of organisms. Gould's implication is that population genetical natural selection would produce forms more adapted to changing conditions than it has or might if it could. The teleology that Reiss ferrets out of Gould lurks in that counterfactual. Selection, Gould argues, is unable to get around developmental constraints. Hence, he concludes, adaptationism is wrong. But, as Reiss rightly points out, the very optimizing assumptions against which Gould launches his glittering polemics are buried in a shallow grave in his way of conceiving of development (267).

Reiss argues that development enters into the evolutionary process not in the way it biases the distribution of available variation by the exertion of evolutionary forces such as selection, but in the way in which the developmental process itself is the source of the variation by which beings as presumptively adaptive as organisms maintain their conditions of existence. "True developmental or generative constraints," Reiss writes, "are better viewed as a process that produces phenotypic variation rather than as constraints on some other process" (327; agreeing with Salazer-Ciudad, Alberch, Müller, and Newman, 329). If Reiss does not say much if anything about Gould's punctuated pattern of macroevolution it is probably because the very idea assumes Gould's constraint-dominated ideas. I get the impression that for Reiss phylogenetic disparity and diversity are no more than the accumulated effects of forks in the road in which conditions of existence were or were not maintained at the organismic level. 
The shift to development as the source of variation is not Reiss's own idea. It is Alberch's and that of others - Gerd Müller, Stuart Newman, and Scott Gilbert, for example - whose conceptions of Evo-devo differ from the Evo-devo of the 1980s with which Gould was associated. Their shared stress on development as the source of phenotypic variation rather than on development as putting phylogenetic constraints on selective retention of genetic variation - their stress, that is, on "the arrival of the fittest," in Gilbert's misleadingly cute formula, rather than "the survival of the fittest" - is brought about by shifting to a new, or rather old, epigenetic conception of organisms. In one way or another, all these writers point out that if the developmental process and the complex way it (as opposed to genes) interacts with the environment is the presumptive and proximate source of potentially adaptive variation, then organisms must be seen as inherently adaptive developmental systems.

Where arguments arise among advocates of this new family of evolutionary theories is on how adaptive ontogenetic processes are in themselves and therefore on what role and importance remains to natural selection. Some have hardly any use for selection at all, proposing autopoietic self-formation or selforganization as a substitute. Others remain Darwinian by casting selection in the eliminative or purifying role that it played before the Modern Synthesis insisted on genetic variation as mere material and adaptive natural selection ranging over it as the "creative" element in evolution. I think Reiss, like Massimo Pigliucci, has a more positive view of natural selection than that. Pigliucci is as dubious about distinguishing drift from selection as Reiss (Pigliucci and Kaplan 2006, 29; Reiss, 229). But Pigliucci sees the developmentalist turn from the perspective of quantitative genetics, developing themes about phenotypic plasticity and evolvability that go back to Dobzhansky and Lewontin (Pigliucci 2001). To that extent he has a more positive view of the causal significance of population genetics than Reiss. Perhaps for this reason he retains an etiological view of adaptedness (Pigliucci and Kaplan 2006, 132-33). He and his philosophical co-author take consequence etiology to offer protection against the design paradigm in both its natural and theological senses. In doing so they do not seem to think that they have entangled themselves in the environmental determinism that Reiss thinks carries design talk with it.

There are many other related views on offer at present and still more are likely to come. I would even venture to say that the developmentalist turn in evolutionary theory is still at the stage of inventing a wide array of related theories rather than perhaps prematurely selecting against some of them. I see Reiss's book as a welcome contribution to this inventive effort. Reiss is also to be commended for realizing that evolutionary biologists cannot ignore, if they are to do their work productively, the conceptual history and philosophy of their discipline. To be sure, anyone who goes back through history to find the roots of current problems runs a risk of dragging the past into an empirically advanced present or conversely of inscribing the present into the past. Still, finding the roots of present practice, if done as responsibly as Reiss does it, increases the likelihood that we may turn up something that throws an unexpected light on business as usual. By reading and thinking hard about the historical roots of present practice, Reiss has written a challenging book that, especially when read in dialogue with other works on his themes, will contribute to facilitating the great transition that evolutionary theory is currently undergoing.

\section{Literature cited}

Brigandt, I. 2009. Accounting for vertebrate limbs: from Owen's homology to novelty in Evo-devo. Philosophy \& Theory in Biology 1: e004.

Coleman, W. 1964. George Cuvier, Zoologist. Cambridge, MA: Harvard University Press.

Dawkins, R. 1996. Climbing Mount Improbable. New York: W.W. Norton.

Depew, D. 2008. Consequence etiology and biological teleology in Aristotle and Darwin. Studies in the History and Philosophy of the Biological and Biomedical Sciences 39: 379-390.

Depew, D. 2009. The rhetoric of Darwin's Origin of Species. In The Cambridge Companion to The Origin of Species. Ed. by M. Ruse and R. Richards. Cambridge: Cambridge University Press.

Depew D. 2010. Adaptation as process: The future of Darwinism and the legacy of Theodosius Dobzhansky. Studies in the History and Philosophy of the Biological and Biomedical Sciences. (doi: 10.1016/j.shpsc.1010.11.006) 
Depew, D. and B. Weber. 1995. Darwinism Evolving: Systems Dynamics and the Genealogy of Natural Selection. Cambridge, MA: MIT Press.

Gilbert, S. and D. Epel. 2009. Ecological Developmental Biology. Sunderland, MA: Sinauer.

Gould, S. and R. Lewontin. 1979. The spandrels of San Marco and the Panglossian paradigm: a critique of the adaptationist programme. Proceedings of the Royal Society-London B. 205: 581-98.

Hodge, M.J.S. 1985. Darwin as a lifelong generation theorist. In The Darwinian Heritage. Ed. by D. Kohn. Cambridge: Cambridge University Press.

Matthen, M. and A. Ariew. (2002). Two ways of thinking about fitness and natural selection. Journal of Philosophy 99: 55-83.

McLaughlin, P. 2001. What Functions Explain: Functional Explanation and Self-Reproducing Systems. Cambridge: Cambridge University Press.

Moore, J. 2007. R.A. Fisher: A faith fit for eugenics. Studies in History and Philosophy of Biological and Biomedical Sciences 38: 110-35.

Neiman, S. 2002. Evil in Modern Thought: An Alternative History of Philosophy. Princeton: Princeton University Press

Nyhart, L. 2009. Embryology and morphology. In The Cambridge Companion to The Origin of Species. Ed. by M. Ruse and R. Richards. Cambridge: Cambridge University Press.

Pigliucci, M. 2001. Phenotypic Plasticity: Beyond Nature and Nurture. Baltimore: Johns Hopkins University Press.

Pigliucci, M. and J. Kaplan. 2006. Making Sense of Evolution: The Conceptual Foundations of Evolutionary Biology. Chicago: University of Chicago Press.

Ruse, M. and R. Richards. (eds) 2009. The Cambridge Companion to The Origin of Species. Cambridge: Cambridge University Press.

Russell, E.S. 1916. Form and Function: A Contribution to the History of Animal Morphology. London: John Murray.

Walsh, D., T. Lewens, and A. Ariew. 2002. The trials of life: natural selection and random drift. Philosophy of Science 69: 452-73.

\section{AGKNOWLEDGMENTS}

I wish to thank an anonymous reviewer and Alan Love for penetrating and helpful comments on an earlier draft of this essay.

Copyright (C) 2010 Author(s).

This is an open-access article distributed under the terms of the Creative Commons Attribution-NonCommercial-NoDerivs license, which permits anyone to download, copy, distribute, or display the full text without asking for permission, provided that the creator(s) are given full credit, no derivative works are created, and the work is not used for commercial purposes.

ISSN 1949-0739 